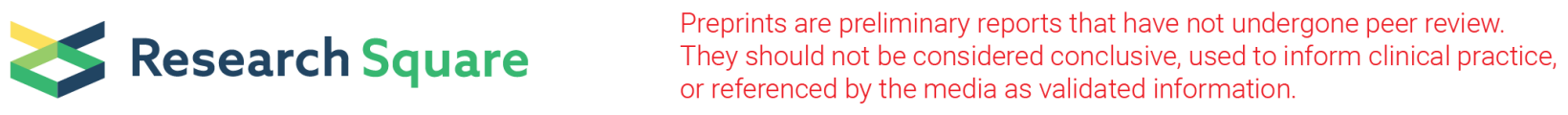

\title{
The Effect of Incubation Temperature On Semen Parameters Before Intra- Uterine Insemination
}

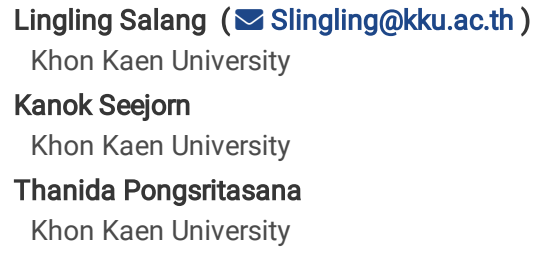

\section{Research Article}

Keywords: Progressive motile sperm, Intrauterine insemination (IUI), room temperature $\left(26^{\circ}-28^{\circ} \mathrm{C}\right)$, body temperature $\left(37^{\circ} \mathrm{C}\right)$, density gradient centrifugation (DGC)

Posted Date: September 2nd, 2021

DOI: https://doi.org/10.21203/rs.3.rs-843825/v1

License: (c) (1) This work is licensed under a Creative Commons Attribution 4.0 International License. Read Full License 


\section{Abstract \\ Objectives}

To evaluate the effect of different incubation temperature between room $\left(26-28^{\circ} \mathrm{C}\right)$ and body $\left(37^{\circ} \mathrm{C}\right)$ temperature on percentage of progressive sperm motility and the optimal incubation period before intrauterine insemination.

\section{Methods}

Seventy-one normal semen samples under WHO 2010 criteria were recruited. All semen was prepared with Density Gradient Centrifugation technique (DGC) and divided into two groups to evaluate sperm motility at $60 \mathrm{~min}$ of incubation time. First group: prepared semen was incubated in room temperature $\left(26^{\circ}-28^{\circ} \mathrm{C}\right)$ and second group: prepared semen was incubated in body temperature $\left(37^{\circ} \mathrm{C}\right)$. Moreover, each group is divided into 4 items for compare sperm motility between both groups in same of incubation time and evaluate the optimal incubation time between the items in the same groups.

\section{Results}

Spermatozoa incubated at body temperature had a significantly higher percentage of progressive sperm motility than those incubated at room temperature $(89.62 \pm 8.02$ vs $85.97 \pm 9.42 ; p<0.01)$. The optimal incubation time at room temperature was 30 minutes and at body temperature was 60 minutes. These results suggest that spermatozoa incubated at $37^{\circ} \mathrm{C}$ for 60 minutes were more likely to have better sperm motility functions for IUI.

\section{Conclusion}

These results suggest that spermatozoa incubated at $37^{\circ} \mathrm{C}$ for 60 minutes were more likely to be effective for use in IUI in terms of sperm motility functions.

\section{Introduction}

The incidence of infertility is increasing every year, especially in South East Asia. ${ }^{1}$ Although the causes of infertility can be defined in females, those of male infertility frequently remain unexplained. ${ }^{2}$ Sperm quality is very important, and laboratory and treatment options are mainly based on sperm quality. ${ }^{3}$ One less invasive and more cost-effective method used to assist in conception is intrauterine insemination (IUI). The success rate of IUI in Europe is approximately $8.3-$ $10.3 \%$ per cycle, and the overall success rate is between 4 and $40 \% .{ }^{4}$ The effectiveness of IUI depends on various factors such as female age, causes of infertility, ovarian stimulation protocol, and sperm motility count ${ }^{5}$. Many studies have suggested that the success of IUI depends substantially on there being a sufficient number of motile sperm after preparation. ${ }^{6-10}$

The aim of sperm preparation before IUI is to maximize the chance of fertilization. Refinement of the sperm preparation procedure is required in order to obtain spermatozoa or elongated spermatids with the highest potential for normal fertilization from gross abnormal semen samples and to increase sperm motility. ${ }^{11}$ The quality of the sperm sample depends on various laboratory factors including 1) sperm preparation method, 2) temperature during sperm preparation, 3) time interval from sperm preparation to IUI, and 4) temperature during the sperm incubation period. There are two common methods used in sperm preparation which are swim-up method and density gradient centrifugation. A previous Cochrane review was not able conclude which of these two was more effective in clinical pregnancy. ${ }^{12}$

After semen are prepared, they are incubated before insemination. There are currently no specific recommendations regarding the optimal time from incubation to IUI. Some studies have suggested that the prolonged sperm incubation may have an adverse effect on sperm nuclear status and that too short of an incubation time may cause un-decondense of sperm nuclease that known of this was a fertilized factor. ${ }^{13}$ However, the majority of studies have reported the maximum sperm motility count to be associated with an incubation time between $40-80$ minutes before sperm insemination. ${ }^{4}$

It is important that the temperature of the testis is approximately $2-3^{\circ} \mathrm{C}$ lower than core body temperature. ${ }^{3}$ Nevertheless, many Assisted Reproductive Technology (ART) laboratories have recommended incubating ejaculated sperm at $37^{\circ} \mathrm{C} .{ }^{14}$ However, few studies have been conducted to compare the effects of different incubation temperatures on sperm motility functions. Furthermore, there is no clear evidence as to the optimum temperature for sperm incubation, due to previous studies yielding inconsistent results. In addition, many of these studies compared different temperatures only at 24 hours of incubation. However, in IUI treatment sperm is only incubated for $30-100$ minutes. Therefore, we set out to study the effects of incubation temperature (room [26 $\left.{ }^{\circ}-28^{\circ} \mathrm{C}\right]$ and body $\left.\left[37^{\circ} \mathrm{C}\right]\right)$ on sperm motility over shorter durations on sperm motility.

\section{Materials And Methods}

This was a prospective experimental study conducted in Srinagarind Hospital, a university hospital in Thailand. The study was approved by the institutional review board of The Khon Kaen University Ethics Committee in Human Research (HE581152). All potential participants were counseled, and their written, informed consent was obtained before participation.

Semen samples were obtained from leftover specimens at fertility clinics from May 2018 - September 2020. Normal semen samples according to the World Health Organization's 2010 eligibility criteria were enrolled. ${ }^{15}$ Frozen-thawed semen and semen that was derived from surgical sperm recovery were excluded. 
Semen was processed using the density gradient method. Following this, the sperm was divided into two groups: the study group (body temperature) and control group (room temperature).

\section{Density gradient centrifugation (DGC)}

A two-layer gradient was prepared using Sil-Select Plus ${ }^{\mathrm{TM}}$ (produced by FerilPro N.V. Industriepark Noord 32,8730 Beernam, Belgium) diluted to $45 \%$ and $90 \%$. Using a sterile pipette, a $0.5 \mathrm{ml}$ sample of liquefied semen was placed on top of the upper layer into a $15 \mathrm{ml}$ conical Falcon tube. The tubes were centrifuged at $1500 \times \mathrm{g}$ for $15 \mathrm{~min}$. The supernatant was then discarded, and the pellet was washed once with $5 \mathrm{ml}$ FetilCult Flushing medium (produced by FerilPro N.V. Industriepark Noord 32, 8730 Beernam, Belgium). The pellet was resuspended in the volume 1 milli letter, and semen parameters were evaluated using CASA. An aliquot was divided into 2 groups (each group $=0.5 \mathrm{ml}$ ) by simple random allocation. The first and second group were suspended in $2 \mathrm{ml}$ culture tubes and incubated for $120 \mathrm{~min}$ at $37^{\circ} \mathrm{C}$ and room temperature $\left(26^{\circ}-28^{\circ} \mathrm{C}\right)$, respectively. Semen parameters were analyzed using CASA (Fig. 1).

\section{Computer Assisted Semen Analysis (CASA)}

All semen samples were analyzed using CASA (version 14; IVOS; 100 Cummings Center, Suite 465E, Beverly, MA 01915 USA). This instrument was maintained and calibrated yearly. Briefly, $10 \mu$ of semen was placed on a dual sided sperm analysis chamber (Hamilton Thorne Biosciences, Beverly, MA, USA) for automatic analysis. At least 200 sperms were counted using CASA to evaluate sperm concentration, sperm motility, and variable sperm motions including sperm movement (rapid, medium, slow, static), average path velocity (VAP), straight line velocity (VSL), curvilinear velocity (VCL), amplitude of lateral head displacement $(A L H)$, straightness (STR = VSL/VAP), and linearity ( $I N=$ VSL/VCL). The CASA settings were adjusted according to the manufacturer's instructions.

\section{Statistical analysis}

Statistical analysis was performed using a paired t-test to compare semen parameters between the two groups and progressive sperm motility within groups, and a linear mixed model was used to evaluate optimal incubation time.

\section{Results}

Seventy-one normal semen samples were enrolled. The baseline characteristics of the sperm are presented in Table 1. The mean age of the donors was $37.3 \pm$ 6.5 years. The mean sperm concentration $\left(10^{6} / \mathrm{mL}\right)$ was $29.07 \pm 6.59$. The mean percentages of progressive sperm motility and normal morphology were $70.18 \pm 10.26$ and $15.56 \pm 2.39$, respectively. 


\begin{tabular}{|c|c|}
\hline Sperm characteristics & Mean \pm SD \\
\hline Age (years) & $37.3 \pm 6.5$ \\
\hline Duration of infertility (months) & $5.5 \pm 1.3$ \\
\hline Baseline semen characteristics & $3.05 \pm 1.28$ \\
\hline - Volume (mL) & $29.07 \pm 6.59$ \\
\hline - Sperm count $\left(\times 10^{6} / \mathrm{mL}\right)$ & $70.18 \pm 10.26$ \\
\hline - Progressive motility (\%) & $13.84 \pm 10.69$ \\
\hline - Total sperm motility $\left(\times 10^{6} / \mathrm{mL}\right)$ & $47.01 \pm 9.55$ \\
\hline - Characteristic of sperm motility & $36.13 \pm 9.10$ \\
\hline - $\operatorname{VAP}(\mu \mathrm{mol} / \mathrm{l} / \mathrm{s})$ & $77.46 \pm 14.62$ \\
\hline • VSL ( $\mu \mathrm{mol} / \mathrm{l} / \mathrm{s})$ & $45.52 \pm 7.10$ \\
\hline$\cdot \operatorname{VCL}(\mu \mathrm{mol} / \mathrm{l} / \mathrm{s})$ & $71.61 \pm 8.19$ \\
\hline • LIN (\%) & $3.96 \pm 0.69$ \\
\hline • STR (\%) & $27.83 \pm 5.42$ \\
\hline - ALH ( $\mu \mathrm{mol} / \mathrm{l} / \mathrm{s})$ & 8.0 \\
\hline$\cdot \mathrm{BCF}(\mathrm{Hz})$ & $15.56 \pm 2.39$ \\
\hline$-\mathrm{PH}$ & $70.5 \pm 5.3$ \\
\hline \multicolumn{2}{|l|}{ - Normal morphology $\left(\times 10^{6} / \mathrm{mL}\right)$} \\
\hline \multicolumn{2}{|l|}{ - Viability (\%) } \\
\hline Abbreviations: & \\
\hline
\end{tabular}

The effects of incubation temperature on progressive motility are shown in Table 2 . The percentage of progressive sperm motility in the body-temperature group (study group) was significantly higher than in the room-temperature group ( $89.62 \pm 8.02$ vs $85.97 \pm 9.42, \mathrm{P}<0.01)$. In addition, all aspects of sperm motility were significantly higher in the study group including curvilinear velocity movement (VCL; 100.2 vs $86.8 ; P<0.01)$, average path velocity (VAP; 63.9 vs 51.9; $P<0.01$ ), straight line velocity (VSL; 54.9 vs $42.7 ; P<0.01$ ), straightness coefficient (STR; 78.8 vs 75.8; $P<0.01$ ), and amplitude of lateral head displacement (ALH; 5.1 vs. $4.7 ; P<0.01 ;$ Table 2$)$. 
Table 2

Semen parameters of each group at baseline and after incubation. Presented as average values and standard deviation at 60 minutes

\begin{tabular}{|c|c|c|c|c|}
\hline Characteristic & $\begin{array}{l}\text { After preparation } \\
\text { Mean (SD) }\end{array}$ & $\begin{array}{l}\text { Room -temperature } \\
\text { Mean (SD) }\end{array}$ & $\begin{array}{l}\text { Body -temperature } \\
\text { Mean (SD) }\end{array}$ & $\begin{array}{l}\text { p-Value } \\
(95 \% \mathrm{Cl}) \\
\text { Between room and body temperature }\end{array}$ \\
\hline Mean sperm concentration $\left(\times 10^{6} / \mathrm{ml}\right.$.) & $23.55 \pm 4.13$ & $22.41 \pm 4.46$ & $22.69 \pm 4.44$ & $\begin{array}{l}<0.01 \\
(0.02-0.55)\end{array}$ \\
\hline Percentage of sperm motility & $86.64 \pm 8.99$ & $85.9 \pm 9.42$ & $89.62 \pm 8.03$ & $\begin{array}{l}<0.01 \\
(2.31-4.98)\end{array}$ \\
\hline Percentage of progressive motility & $75.45 \pm 11.56$ & $72.7 \pm 12.91$ & $78.49 \pm 10.35$ & $\begin{array}{l}<0.01 \\
(2.94-8.55)\end{array}$ \\
\hline Mean total sperm motility count $\left(\times 10^{6} / \mathrm{ml}\right.$.) & $22.61 \pm 4.55$ & $22.41 \pm 4.46$ & $22.69 \pm 4.44$ & $\begin{array}{l}<0.01 \\
(0.27-0.66)\end{array}$ \\
\hline Motility characteristics & $57.16 \pm 14.39$ & $51.98 \pm 14.49$ & $63.98 \pm 13.90$ & $<0.01(9.91-14.09)$ \\
\hline - VAP $(\mu \mathrm{mol} / \mathrm{l} / \mathrm{s}$ & $48.2 \pm 14.47$ & $42.77 \pm 13.55$ & $54.49 \pm 14.0$ & $<0.01(9.54-13.88)$ \\
\hline - VSL ( $\mu \mathrm{mol} / \mathrm{l} / \mathrm{s})$ & $94.19 \pm 18.88$ & $86.82 \pm 18.40$ & $100.2 \pm 17.86$ & $<0.01(10.85-15.99)$ \\
\hline$\cdot \operatorname{VCL}(\mu \mathrm{mol} / \mathrm{l} / \mathrm{s})$ & $46.75 \pm 6.53$ & $45.62 \pm 6.62$ & $51.02 \pm 8.69$ & $<0.01(4.02-6.79)$ \\
\hline • LIN (\%) & $76 \pm 6.62$ & $75.81 \pm 6.86$ & $78.81 \pm 6.40$ & $<0.01(1.60-4.39)$ \\
\hline • STR (\%) & $4.75 \pm 0.16$ & $4.71 \pm 0.65$ & $5.19 \pm 4.21$ & $<0.01(0.54-1.49)$ \\
\hline $\begin{array}{l}\cdot \operatorname{ALH}(\mu \mathrm{mol} / \mathrm{l} / \mathrm{s}) \\
\cdot \operatorname{BCF}(\mathrm{Hz})\end{array}$ & $30.25 \pm 4.72$ & $30.58 \pm 4.59$ & $31.35 \pm 4.41$ & $<0.01(0.12-1.44)$ \\
\hline
\end{tabular}

The optimal incubation time of prepared sperm, at which the percentage of sperm motility and other motility parameters were the highest, was 60 min and 30 min at body and room temperature, respectively (Fig. 2; Table 3). 
Table 3

Comparison of semen parameters at various incubation times at each temperature. Presented as average values and standard deviation.

\begin{tabular}{|c|c|c|c|c|c|c|c|c|c|c|}
\hline \multirow{2}{*}{$\begin{array}{l}\text { Incubation } \\
\text { time } \\
\text { (min.) }\end{array}$} & \multirow{2}{*}{$\begin{array}{l}\text { Tempera- } \\
\text { ture }\end{array}$} & \multirow[t]{2}{*}{ Motility (\%) } & \multirow{2}{*}{$\begin{array}{l}\text { Progressive } \\
\text { motility } \\
(\%)\end{array}$} & \multicolumn{7}{|c|}{ Motility characteristics } \\
\hline & & & & $\begin{array}{l}\text { VAP } \\
(\mu \mathrm{m} / \mathrm{s})\end{array}$ & $\begin{array}{l}\text { VSL } \\
(\mu \mathrm{m} / \mathrm{s})\end{array}$ & $\begin{array}{l}\text { VCL } \\
(\mu \mathrm{m} / \mathrm{s})\end{array}$ & $\begin{array}{l}\text { LIN } \\
(\%)\end{array}$ & $\begin{array}{l}\text { STR } \\
(\%)\end{array}$ & $\begin{array}{l}\text { ALH } \\
(\mu \mathrm{m})\end{array}$ & BCF \\
\hline \multirow[t]{4}{*}{30} & Room & $86.01 \pm 8.99$ & $74.45 \pm 10.92$ & $55.16 \pm 13.87$ & $45.11 \pm 13.19$ & $92.45 \pm 18.41$ & $45.31 \pm 6.58$ & $74.32 \pm 7.17$ & $4.79 \pm 0.56$ & 30.0: \\
\hline & Body & $88.73 \pm 8.31$ & $78.38 \pm 9.33$ & $61.81 \pm 12.27$ & $51.86 \pm 11.97$ & $99.09 \pm 17.14$ & $49.23 \pm 4.86$ & $77.32 \pm 6.37$ & $4.74 \pm 0.50$ & 31.4 \\
\hline & \multirow{2}{*}{$\begin{array}{l}\text { p-value } \\
(95 \% \mathrm{Cl})\end{array}$} & $<0.01$ & $<0.01$ & $<0.01$ & $<0.01$ & $<0.01$ & $<0.01$ & $<0.01$ & 0.34 & $<0.0$ \\
\hline & & $(1.33-4.11)$ & $(1.84-6.00)$ & $(4.32-8.94)$ & $(4.56-8.93)$ & $(4.06-9.22)$ & $\begin{array}{l}(2.72- \\
5.14)\end{array}$ & $\begin{array}{l}(1.12- \\
4.18)\end{array}$ & $\begin{array}{l}(-0.06- \\
0.18)\end{array}$ & $\begin{array}{l}(0.70 \\
2.26)\end{array}$ \\
\hline \multirow[t]{4}{*}{60} & Room & $85.97 \pm 9.42$ & $72.4 \pm 12.90$ & $51.98 \pm 14.04$ & $42.77 \pm 13.55$ & $86.68 \pm 18.36$ & $45.62 \pm 6.63$ & $75.82 \pm 6.82$ & $4.71 \pm 0.64$ & 30.5\{ \\
\hline & Body & $89.62 \pm 8.03$ & $78.49 \pm 10.34$ & $63.98 \pm 13.89$ & $54.48 \pm 14.0$ & $100.42 \pm 17.86$ & $51.02 \pm 6.88$ & $78.82 \pm 6.40$ & $5.91 \pm 0.50$ & 31.31 \\
\hline & \multirow{2}{*}{$\begin{array}{l}\text { p-value } \\
(95 \% \mathrm{Cl})\end{array}$} & $<0.01$ & $<0.01$ & $<0.01$ & $<0.01$ & $<0.01$ & $<0.01$ & $<0.01$ & 0.35 & 0.02 \\
\hline & & $(2.31-4.98)$ & $(2.94-8.55)$ & $(9.9-14.1)$ & $\begin{array}{l}(9.53- \\
13.87)\end{array}$ & $\begin{array}{l}(10.84- \\
15.99)\end{array}$ & $\begin{array}{l}(4.02- \\
6.79)\end{array}$ & $(1.6-4.39)$ & $\begin{array}{l}(-0.54- \\
1.4)\end{array}$ & 0.12 \\
\hline \multirow[t]{4}{*}{90} & Room & $83.81 \pm 11.34$ & $70.55 \pm 12.58$ & $51.43 \pm 13.18$ & $41.66 \pm 12.53$ & $85.46 \pm 17.26$ & $45.17 \pm 7.17$ & $73.88 \pm 7.10$ & $4.71 \pm 0.54$ & $29.5:$ \\
\hline & Body & $88.67 \pm 8.89$ & $77.30 \pm 8.34$ & $61.2 \pm 15.17$ & $51.64 \pm 14.73$ & $97.26 \pm 20.52$ & $49.85 \pm 6.84$ & $78.05 \pm 6.18$ & $4.67 \pm 0.50$ & 30.4: \\
\hline & \multirow{2}{*}{$\begin{array}{l}\text { p-value } \\
(95 \% \mathrm{Cl})\end{array}$} & $<0.01$ & $<0.01$ & $<0.01$ & $<0.01$ & $<0.01$ & $<0.01$ & $<0.01$ & 0.42 & 0.03 \\
\hline & & $(2.75-6.96)$ & $(4.38-9.14)$ & $\begin{array}{l}(6.72- \\
12.83)\end{array}$ & $(7.10-12.87)$ & $(7.99-15.6)$ & $\begin{array}{l}(3.31- \\
6.27)\end{array}$ & $\begin{array}{l}(2.79- \\
5.54)\end{array}$ & $\begin{array}{l}(-0.06- \\
0.14)\end{array}$ & $\begin{array}{l}(-1.6\} \\
-0.06\end{array}$ \\
\hline \multirow[t]{4}{*}{120} & Room & $83.87 \pm 11.78$ & $67.29 \pm 11.72$ & $47.19 \pm 12.76$ & $38.04 \pm 12.49$ & $81.75 \pm 17.09$ & $42.92 \pm 7.33$ & $72.64 \pm 8.62$ & $4.61 \pm 0.58$ & 28.8 \\
\hline & Body & $87.14 \pm 9.80$ & $74.89 \pm 9.93$ & $59.06 \pm 15.07$ & $49.77 \pm 14.77$ & $94.42 \pm 20.41$ & $48.62 \pm 6.59$ & $77.25 \pm 6.65$ & $4.64 \pm 0.67$ & $30.0 !$ \\
\hline & \multirow{2}{*}{$\begin{array}{l}\text { p-value } \\
(95 \% \mathrm{Cl})\end{array}$} & $<0.01$ & $<0.01$ & $<0.01$ & $<0.01$ & $<0.01$ & $<0.01$ & $<0.01$ & 0.70 & 0.01 \\
\hline & & $(1.38-5.15)$ & $(5.43-9.74)$ & $\begin{array}{l}(8.91- \\
14.23)\end{array}$ & $\begin{array}{l}(8.88- \\
14.55)\end{array}$ & $(8.66-16.66)$ & $\begin{array}{l}(4.35- \\
7.02)\end{array}$ & $\begin{array}{l}(3.57- \\
5.64)\end{array}$ & $\begin{array}{l}(-0.18- \\
0.12)\end{array}$ & $\begin{array}{l}(0.26 \\
2.14)\end{array}$ \\
\hline
\end{tabular}

Abbreviations: VCL, Curvilinear velocity; VAP, Average path velocity; VSL, Straight line velocity, LIN, Linearity; BCF, Beat cross frequency; ALH, Amplitude of lat $\epsilon$ head displacement; STR, Straightness; Cl, confidence interval

\section{Discussion And Conclusion}

This study used varying temperatures and periods for sperm incubation to evaluate the effect of temperature on progressive sperm motility. The spermatozoa had been processed within the similar condition (density gradient centrifugation). The spermatozoa incubated in $37^{\circ} \mathrm{C}$ temperature had significantly higher forward motility (VCL, VAP, VSL, STR and ALH) compared to control spermatozoa. The optimal incubation time for spermatozoa incubated at body and room temperature was 60 minutes and 30 minutes, respectively.

We found that all of sperm motility parameters were higher in the samples incubated at $37^{\circ} \mathrm{C}$ than those incubated at room temperature. These results are consistent with those of previous studies. ${ }^{16,17}$ Franken et al., for example, found that incubation at $34^{\circ} \mathrm{C}$ led to better sperm motility than at $25^{\circ} \mathrm{C}$. In addition, 2008 Küçük T, et al.; reported a significantly higher pregnancy rate from sperm incubated at a higher temperature $\left(40^{\circ} \mathrm{C}\right) .{ }^{[6]}$ These results were confirmed by ART laboratories studies, which found that $37^{\circ} \mathrm{C}$ was an appropriate temperature for sperm incubation. Although some previous studies have reported better sperm motility parameters at lower temperatures $\left(20^{\circ} \mathrm{C}-25^{\circ} \mathrm{C}\right)$, the sperm in these studies were incubated from $22-24$ hours.

Our study found that the appropriate prepared sperm incubation time was 60 minutes at $37^{\circ} \mathrm{C}$ and 30 minutes at room temperature, which was consistent with the results of previous studies. ${ }^{16,17}$ Fauque P. et al reported that the optimal time for sperm incubation for IUI process was $40-80$ minutes. ${ }^{18}$ In IUI, prepared spermatozoa are usually incubated for 30-90 minutes before injection into the uterine cavity, making prolonged spermatozoa incubation unnecessary. ${ }^{4}$

\section{Strengths and limitations}

This study used samples of the same semen to compare room and body temperature incubation, which reduced the possibility of confounding factors and selection bias, making the results accurate and reliable. A limitation of this study is that we did not evaluate other sperm functions such as sperm capacitation, acrosome reaction, and spermatozoa-zona binding.

\section{Implications for practice and further research}

Choosing the best sperm quality is important for improving both the outcomes and safety of IUI. ${ }^{16,18,19}$ Based on the results of this study, spermatozoa that were incubated at $37^{\circ} \mathrm{C}$ for 60 minutes had higher sperm motility parameters than those incubated at $26^{\circ}-28^{\circ} \mathrm{C}$, which may lead to improved fertility outcomes in IUI. Further study is needed to confirm the efficacy of this method in terms of clinical outcomes such as pregnancy and live birth rates. 


\section{Conclusion}

These results suggest that spermatozoa incubated at $37^{\circ} \mathrm{C}$ for 60 minutes were more likely to be effective for use in IUI in terms of sperm motility functions.

\section{Declarations}

\section{Author contributions}

All of the authors participated in the preparation of this manuscript and have read and approved the final draft.

\section{Declaration of Competing Interest}

The authors declare that they have no known competing financial interests or personal relationships that could have appeared to influence the work reported in this paper.

\section{Acknowledgment}

The authors would thank Dylan Southard for his assistance with the English-language presentation of the manuscript, as well as the Khon Kaen University Faculty of Medicine Research and Development Fund (Thailand) for funding.

\section{Ethical consideration}

The Human Research Ethics Committee of Khon Kaen University reviewed and approved the study per the Helsinki Declaration and the Good Clinical Practice Guidelines (HE581152).

\section{Consent for publication}

All of the authors consent to publishing and hereby grant the Publisher exclusive license of the full copyright.

\section{Disclosures of potential conflicts of interest}

Salang L. declares that he has no conflict of interest

Seejorn K. declares that he has no conflict of interest

Pongsritasana T. declares that he has no conflict of interest

\section{Funding statement}

The study received funding support from the Faculty of Medicine, Khon Kaen University, Thailand (Grant number IN63341).

\section{Availability of data and material}

Data and materials are available upon request.

\section{References}

1. Mascarenhas, M. N. et al. Regional, and Global Trends in Infertility Prevalence Since 1990: A Systematic Analysis of 277 Health Surveys.PLoS Med9,e1001356(2012).

2. Best practices of ASRM and ESHRE: a journey through reproductive medicine - Best_Practices_of_ASRM_and_ESHRE-noprint.pdf.

3. Elder, K. \& Dale, B. In-Vitro Fertilization (in (Cambridge University Press, 2011).

4. Fauque, P. et al. Clinical success of intrauterine insemination cycles is affected by the sperm preparation time.Fertil. Steril.101,1618-1623.e1-3 (2014).

5. ESHRE Capri Workshop Group. Intrauterine insemination. Hum. Reprod. Update15,265-277(2009).

6. Küçük, T., Sözen, E. \& Buluç, B. Effect of heat-induced hypermotility on pregnancy rate in intrauterine insemination for male factor infertility associated with asthenospermia: a prospective, randomized, controlled study.J. Assist. Reprod. Genet.25,235-238(2008).

7. Nikbakht, R. \& Saharkhiz, N. The influence of sperm morphology, total motile sperm count of semen and the number of motile sperm inseminated in sperm samples on the success of intrauterine insemination.Int. J. Fertil. Steril.5,168-173(2011).

8. Dorjpurev, U. et al. Effect of semen characteristics on pregnancy rate following intrauterine insemination.J. Med. Investig. JM/58,127-133(2011).

9. Tay, P. Y. S., Raj, V. R. M., Kulenthran, A. \& Sitizawiah, O. Prognostic factors influencing pregnancy rate after stimulated intrauterine insemination.Med. J. Malaysia62,286-289(2007).

10. Ombelet, W., Dhont, N., Thijssen, A., Bosmans, E. \& Kruger, T. Semen quality and prediction of IUI success in male subfertility: a systematic review. Reprod. Biomed. Online28,300-309(2014).

11. Boomsma, C. M., Heineman, M. J., Cohlen, B. J. \& Farquhar, C. Semen preparation techniques for intrauterine insemination. in Cochrane Database of Systematic Reviews (John Wiley \& Sons, Ltd, 1996). 
12. Boomsma, C. M., Heineman, M. J., Cohlen, B. J. \& Farquhar, C. Semen preparation techniques for intrauterine insemination. Cochrane Database Syst. Rev, CD004507, https://doi.org/10.1002/14651858.CD004507.pub3 (2007).

13. García, J., Noriega-Hoces, L. \& Gonzales, G. F. Sperm chromatin stability and its relationship with fertilization rate after intracytoplasmic sperm injection (ICSI) in an assisted reproduction program.J. Assist. Reprod. Genet.24,587-593(2007).

14. van der Westerlaken, L., Naaktgeboren, N., Verburg, H., Dieben, S. \& Helmerhorst, F. M. Conventional in vitro fertilization versus intracytoplasmic sperm injection in patients with borderline semen: a randomized study using sibling oocytes. Fertil. Steril.85,395-400(2006).

15. WHO | WHO laboratory manual for the examination and processing of human semen. WHO http://www.who.int/reproductivehealth/publications/infertility/9789241547789/en/.

16. de Araújo, L. F. et al. Efficacy of sperm motility after processing and incubation to predict pregnancy after intrauterine insemination in normospermic individuals. Reprod. Biol. Endocrinol.11,101(2013).

17. Chan, P. J., Corselli, J. U., Patton, W. C., Jacobson, J. D. \& King, A. Enhanced fertility after heat-induced hyperactivation.Fertil. Steril.69,118-121(1998).

18. Fauque, P. et al. Clinical success of intrauterine insemination cycles is affected by the sperm preparation time.Fertil. Steril.101,1618-1623.e3(2014).

19. de Araújo, L. F. P. et al. Efficacy of sperm motility after processing and incubation to predict pregnancy after intrauterine insemination in normospermic individuals. Reprod. Biol. Endocrinol. RBE11,101(2013).

\section{Figures}

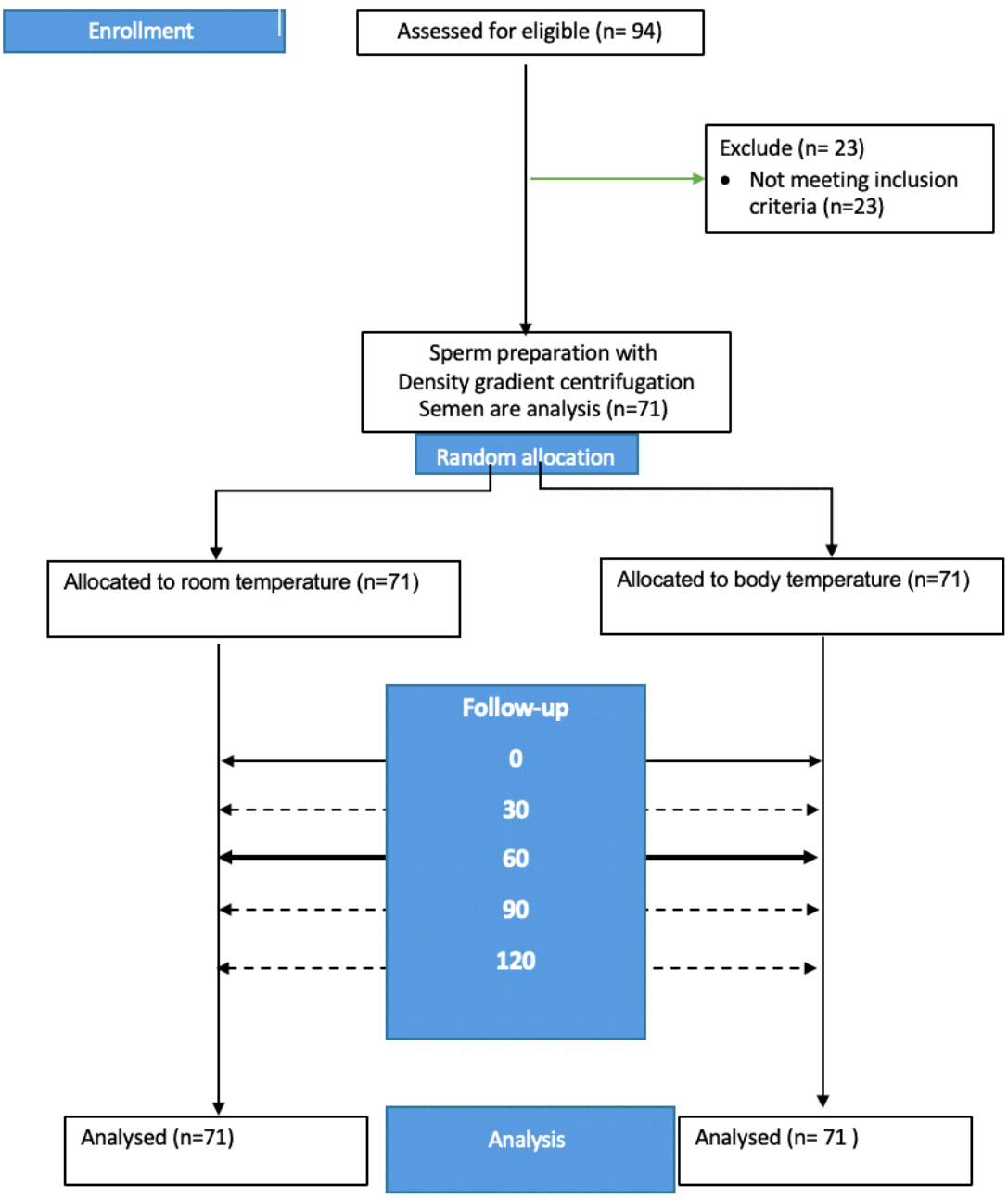

Figure 1

Study flow 


\section{Optimal incubation time}

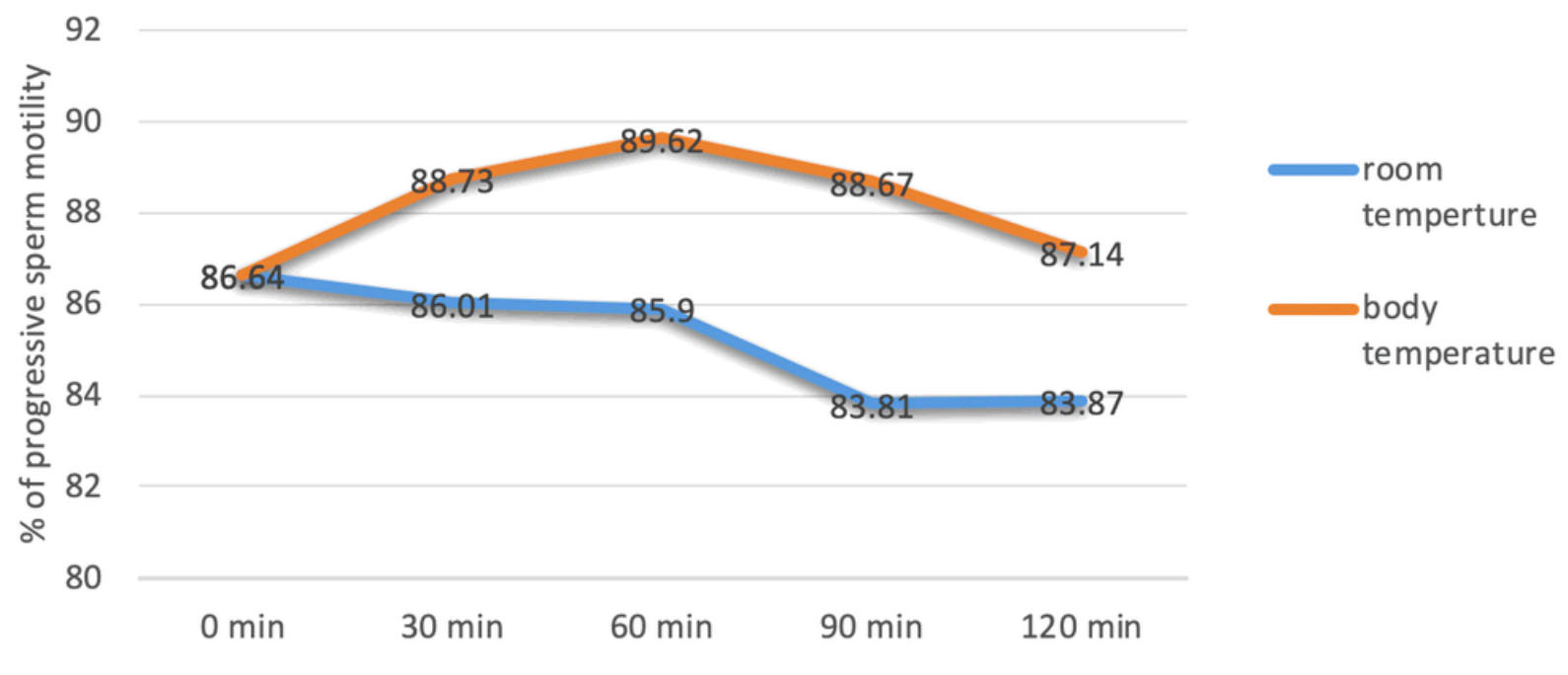

Figure 2

Optimal incubation times at each temperature 